\title{
Erratum to: Do cervical spine X-rays for trauma have clinically significant incidental findings?
}

\author{
L. Koren - A. Simonovich · D. Norman • \\ S. Israelit $\cdot$ M. Jerdev $\cdot$ R. Shreter • \\ Y. Yagil $\cdot$ R. Rozenberg $\cdot$ E. Peled
}

Published online: 23 May 2013

(C) Springer-Verlag Berlin Heidelberg 2013

\section{Erratum to: Eur J Trauma Emerg Surg}

\section{DOI 10.1007/s00068-013-0290-6}

In the published original article, the family name of the coauthor R. Sherter is not given correct. The correct name is:

R. Shreter (not Sherter).

The online version of the original article can be found under doi:10.1007/s00068-013-0290-6.

L. Koren $(\varangle) \cdot$ D. Norman $\cdot$ E. Peled Division of Orthopedics, Rambam Health Care Campus, P.O. Box 9602, Haifa 31096, Israel

e-mail: 1.koren.lior@gmail.com

A. Simonovich · M. Jerdev · R. Shreter · Y. Yagil ·

R. Rozenberg

Department of Radiology, Rambam Health Care Campus,

Haifa, Israel

S. Israelit

Department of Emergency Medicine, Rambam Health Care

Campus, Haifa, Israel 